\title{
Proceedings of the 2021 Cannabis Clinical Outcomes Research Conference
}

\author{
Amie J. Goodin ${ }^{\mathrm{a}-\mathrm{c}}$ Debbie L. Wilson ${ }^{\mathrm{a}}$ Robert L. Cook ${ }^{\mathrm{c}-\mathrm{e}}$ Yan Wang ${ }^{\mathrm{c}, \mathrm{d}}$ \\ Joshua Brown ${ }^{\mathrm{a}-\mathrm{c}}$ Almut G. Winterstein ${ }^{\mathrm{a}-\mathrm{d}}$ \\ a Pharmaceutical Outcomes and Policy, University of Florida, Gainesville, FL, USA; ${ }^{b}$ Center for Drug Evaluation \\ and Safety (CoDES), University of Florida, Gainesville, FL, USA; ${ }^{c}$ Consortium for Medical Marijuana Clinical \\ Outcomes Research, University of Florida, Gainesville, FL, USA; ${ }^{d}$ Department of Epidemiology, University of \\ Florida, Gainesville, FL, USA; ${ }^{\text {e}}$ Department of Medicine, University of Florida, Gainesville, FL, USA
}

\section{Keywords}

Conference proceedings · Medical marijuana - Cannabis ·

Marijuana clinical outcomes

\begin{abstract}
The Cannabis Clinical Outcomes Research Conference (CCORC) 2021 was held virtually on April 8 and 9, 2021. The conference was hosted by the Consortium for Medical Marijuana Clinical Outcomes Research, a research organization instituted by the state legislature of Florida in the United States. The inaugural annual CCORC 2021 was organized as a scientific meeting to foster and disseminate research on medical marijuana (MM) clinical outcomes, while promoting engagement among MM researchers, patients, clinicians, policymakers, and industry partners. Key conference themes included: (a) the disconnect between policy, practice, and evidence and steps towards reconciliation, (b) approaches to overcome common barriers to MM research, and (c) the use of focused translational approaches utilizing both mechanistic and clinical research methodology to tackle the complexities of MM outcomes. CCORC 2022 is planned for spring 2022 in Orlando, Florida, United States.
\end{abstract}

(c) 2021 The Author(s)

Published by S. Karger AG, Basel
Florida is one of 36 states in the United States that permits approval of medical marijuana (MM) for use as a treatment for certain debilitating conditions, with over 450,000 Floridians certified to receive MM to date [1]. While offering great promise to patients whose conditions may not be responsive to approved medications, evidence on MM's efficacy and safety for the vast majority of promoted or approved conditions is limited $[2,3]$. Moreover, MM varies significantly in terms of its specific components and modes of administration, but little is known about how MM improves clinical outcomes and what components, doses, and delivery methods provide the optimally balanced risk-benefit ratio. As summarized in a sentinel National Academy of Science, Engineering and Medicine (NASEM) report, the lack of scientific, clinical research prevents the development of evidencebased policies and clinical guidelines; yet, research progress is hampered by access, financial, and regulatory barriers [2].

To address the need for rigorous evidence on the safety and effectiveness of MM for the various patient populations who are seeking certification for use, the Florida state legislature established the Consortium for Medical Marijuana Clinical Outcomes Research (the Consortium, hereafter) with the charge to conduct, disseminate, karger@karger.com www.karger.com $/ \mathrm{mca}$

Karger $\stackrel{\text { ' }}{5}$

BOPEN ACCESS
(C) 2021 The Author(s)

Published by S. Karger AG, Basel

This is an Open Access article licensed under the Creative Commons Attribution-NonCommercial-4.0 International License (CC BY-NC) (http://www.karger.com/Services/OpenAccessLicense), applicable to the online version of the article only. Usage and distribution for commercial purposes requires written permission.
Correspondence to:

Almut G. Winterstein, almut@ cop.ufl.edu 
and support rigorous scientific research. The Consortium fosters MM clinical outcomes research through a clinical research core, an evidence core, a grants program, a research data repository (i.e., the MEdical Marijuana Clinical Outcomes RepositorY [MEMORY]), and an outreach program $[4,5]$. For more information about the Consortium, see www.mmjoutcomes.org. These proceedings summarize the scientific content and key messages of the Consortium's Cannabis Clinical Outcomes Research Conference (CCORC), which was held in April 2021 [5].

\section{Conference Format}

CCORC 2021 was held virtually in response to the COVID-19 pandemic (for more information, see www.ccorc. mmjoutcomes.org) on April 8 and 9, 2021 and drew over 225 registrants - including 43 students - with representation among attendees from 31 US states and five countries (Germany, Italy, Mexico, United Kingdom, and United States). The inaugural CCORC had three objectives: (1) to disseminate research findings on the use, efficacy, safety, and other relevant outcomes of medical cannabis, (2) to provide a venue for sharing medical cannabis clinical research and education on medical cannabis, and (3) to foster engagement of stakeholders and collaboration among researchers [5].

The 2021 CCORC virtual format included a mix of keynote presentations, featured oral presentations, poster sessions, panel discussions, and networking sessions [6]. The presentations were recorded and posted to the conference website along with the poster presentations and program details, where the presentations will be available online for 6 months to registrants. A total of 35 abstracts were accepted for presentation following peer review and are included in this issue of Medical Cannabis and Cannabinoids. Three core themes evolved from presentations and discussions during the conference.

\section{Working toward Evidence-Based Policy}

Specific state policies rather than evidence-based clinical guidelines currently define the use of MM. Further, while the need for evidence to inform policy is well recognized, policy in the US limits the progress of research to deliver such evidence. This theme was introduced by Dr. R. Lorraine Collins, Associate Dean for Research and Professor in Community Health and Health Behavior in the School of Public Health and Health Professions at the University of Buffalo, who served on the NASEM Committee that produced the report entitled "The Health Effects of Cannabis and Cannabinoids: The Current State of Evidence and Recommendations for Research" [2]. Her CCORC 2021 keynote presentation "Cannabis Science vs. Policies: Reconciling the Disconnect" started with a broad overview of the variations of approved indications, MM types, and relevant policies in the different states. She contrasted available evidence with current policy and practice, highlighting conditions with (e.g., chronic pain, spasticity related to multiple sclerosis) and without (e.g., glaucoma, cancer, Parkinson's disease) evidence in support of efficacy. She also discussed the potential impact of the legalization of cannabis on patient and public safety. Based on (a) demonstrated variation in MM policies across states, (b) the disconnect between policy and evidence, and (c) the complexity of the targeted health conditions as well as (d) the complexity of the cannabis plant and its products, Dr. Collins emphasized the critical need for research. Her proposed research agenda encompasses pharmacological studies as well as well-controlled clinical trials with special emphasis on dosage forms, dose and potencies, and understudied conditions. This packed agenda, however, stands in stark contrast to the current regulatory impediments to clinical MM studies. Dr. Collins advocated for the removal of the US Federal Government schedule 1 designation of cannabis to facilitate research and coordinate state policy. She closed her presentation suggesting that research must catch up with policy and "Big Cannabis" to provide the basis for evidence-based policy and public health messaging.

An interesting perspective in regard to current public health messaging was provided by one of the featured conference abstracts presented by Krystal Hemingway, Doctor of Nurse Practitioner Candidate in the College of Nursing at Florida State University. This study assessed Florida healthcare providers' knowledge, practices, and attitudes of MM use and identified a lack of knowledge paired with skepticism and negative feelings about MM use. This suggests that Florida patients who qualify and might use MM may have limited access to MM and may have providers with biases regarding MM. Suggested interventions to address these issues included: a mandatory $\mathrm{CE}$ module for Florida providers, specialization of MM consultants who could provide support to MM treatment centers, patients, and providers, and the use of pharmacies for MM dispensing. 


\section{Overcoming Challenges to Improve Cannabis Research Rigor}

Though a rocky road in the current US regulatory environment, there are ways to conduct high-quality research on the effects of MM. This was the key message from Dr. Donald Abrams, Professor in Medicine in the University of California in San Francisco, a pioneer of cannabis research, who has conducted multiple clinical trials evaluating cannabinoids in cancer patients, sickle cell patients, and human immunodeficiency virus (HIV)infected patients [7-10] and also served on the NASEM Committee on the Health Effects of Marijuana [2]. Dr. Abrams' presentation entitled "Clinical Trials of Cannabis in Cancer and Sickle Cell Pain: 'Not As Easy As It Looks'!” described the historical (dating back to the early 1990s) and current challenges of conducting clinical cannabis research including obtaining funding, subject recruitment, access to products, and standardization of delivery modes and doses under controlled trial conditions. Providing a historical overview of his team's progress in MM research, he highlighted both problems and solutions. Dr. Abrams encouraged use of the cannabis products made available for research from the National Institute on Drug Abuse (NIDA), but also highlighted the differences in those products from the MM products in current use. He introduced his team's solutions to standardized MM administration (his team chose to use a dry flower vaporizer) and approaches to overcome participant recruitment difficulties resulting from restrictions and study requirements. Dr. Abrams emphasized the following solutions to deliver timely evidence on MM efficacy and safety: (1) removal of impeding regulatory barriers, such as the federal schedule 1 designation, (2) access to standardized cannabis products as well as the broad range of marketed products, (3) a diverse network of funders supporting cannabis and cannabinoid research, and (4) an effective infrastructure to support enrollment of study participants.

Overcoming barriers was further discussed in a panel session entitled "Research and Regulatory Barriers" that was chaired by cannabis researcher Dr. Shanna Babalonis (College of Medicine, University of Kentucky) and included Dr. Donald Abrams (Department of Medicine, University of California in San Francisco), Dr. Jacqueline Sagen (Miller College of Medicine, University of Miami), Dr. Chinazo Cunningham (Department of Medicine, Albert Einstein College of Medicine), and Dr. Jennifer Wilkerson (College of Pharmacy, University of Florida). While regulatory barriers and institutional fears impeding research with controlled substances were recognized, Dr.
Wilkerson suggested that junior investigators in pharmacology can begin their work using commercially available, non-scheduled cannabidiol products. This strategy was exemplified by one of the featured conference abstracts presented by Dr. Azari who studied the intranasal application of cannabinoids for treatment of glioblastoma in rats.

The panel revisited the need for standardized products (with defined THC content and reproducible delivery methods) for formal efficacy and safety studies on the one hand, but also emphasized that the broad range of products and dosage forms requires rigorous study - an endeavor that is becoming increasingly complex as the range of products, including an assortment of edibles with difficult-to-standardize content or topicals with unknown pharmacokinetic properties, is increasing. This was also emphasized by one of the featured conference abstracts presented by Dr. Robert Cook, Professor in Medicine and Epidemiology at the University of Florida, who reported the types of cannabis products used, the common dosages, and the administration routes in adults with HIV using data from the Marijuana and Potential Long-term Effects (MAPLE) Study. Dr. Cook discussed the challenges in measuring the quantity or dose of cannabis products consumed, especially for persons smoking marijuana flower.

\section{Translating Evidence to Clinical Practice}

The rapid uptake of MM by patients and clinicians stands in stark contrast to the available evidence; however, a focused translational research agenda that unites mechanistic and clinical research can deliver the necessary insight to better inform patient-involved clinical decision-making. Dr. Ziva Cooper, Associate Professor in Psychiatry and Biobehavioral Science and the Director of Cannabis Research Initiative at the University of California Los Angeles, and also a member of the NASEM Committee on the Health Effects of Marijuana, illustrated this paradigm in her presentation entitled "Controlled $\mathrm{Hu}$ man Studies Investigating Cannabis Constituents for Pain: A Translational Perspective." Dr. Cooper took the audience on a comprehensive excursion on the evidence in support of the efficacy of MM in treatment of pain. Discussing both mechanistic and clinical findings, Dr. Cooper highlighted that THC aids in the management of pain, that terpenes may also reduce pain, and that cannabis constituents are potentially safe strategies to reduce opioid reliance. In contrast, there is little evidence for the use of cannabidiol alone for pain management. Dr. Cooper emphasized that rigorously controlled studies corre- 
lating specific components of cannabis products with their unique health-related outcomes including opioid use risks are still needed.

Another piece of evidence in fully understanding the contribution of MM in the management of chronic pain was presented by Dr. Yan Wang, Assistant Professor in Epidemiology at the University of Florida, who presented results from a 12-month prospective pilot study investigating MM and its impact on health outcomes where data were collected directly from patients using smartphonedelivered surveys. Patient reports included positive findings on the efficacy of MM for chronic pain (e.g., 78.6\% reported MM to be moderately to extremely effective in managing chronic pain), but also on adverse effects (e.g., $42.9 \%$ reported side effects) of MM for pain management.

The CCORC 2021 fostered the dissemination and discussion of research on the safety and effectiveness of MM. Recognizing the disconnect between policy, practice, and the available guiding evidence, the CCORC speakers' presentations detail the urgently needed, focused translational research agenda that supports policy, clinical practice, and public health messaging. Accounts by experienced MM researchers offered helpful guidance on how to overcome barriers to start or expand a successful MM research program. The second CCORC is planned for spring 2022 in Orlando, Florida, United States.

\section{Acknowledgement}

Consortium leadership would like to thank and acknowledge members of the Consortium Board, representing the Consortium nine member universities (Florida Agricultural and Mechanical
University, Florida Atlantic University, Florida Gulf Coast University, Florida International University, Florida Memorial University, Florida State University, University of Central Florida, University of Florida, and University of Miami); members of the scientific program committee (Dr. Amie J Goodin, University of Florida, Dr. Yan Wang, University of Florida, Dr. Jeevan Jyot, University of Florida, Dr. Dalton Dietrich, University of Miami, Dr. Sari Parikoff, Florida Golf Coast University); UF Lifelong Learning for development of the conference website and media support; Florida state legislature for the funding, and the many organizations and institutions that contributed to this successful CCORC.

\section{Conflict of Interest Statement}

The authors have no conflicts of interest to declare.

\section{Funding Sources}

This work was funded by the Consortium for Medical Marijuana Clinical Outcomes Research via Florida state legislature. The funders had no role in the design and conduct of the study; collection, management, analysis, and interpretation of the data; preparation, review, or approval of the manuscript; and decision to submit the manuscript for publication.

\section{Author Contributions}

Concept and design: Wilson, Goodin, Winterstein. Acquisition, analysis, or interpretation of data: all authors. Drafting of the manuscript: Wilson, Goodin, Winterstein. Critical revision of the manuscript for important intellectual content: all authors. Obtained funding: Cook, Winterstein. Administrative, technical, or material support: Wilson, Goodin, Winterstein. Supervision: Goodin, Winterstein.

\section{References}

1 National Conference of State Legislatures. State Medical Marijuana Laws 2021 [updated April 5, 2021; cited: April 22, 2021]. Available from: https://www.ncsl.org/research/health/ state-medical-marijuana-laws.aspx.

2 National Academies of Sciences E, and Medicine; Health and Medicine Division; Board on Population Health and Public Health Practice; Committee on the Health Effects of Marijuana: An Evidence Review and Research Agenda. The Health Effects of Cannabis and Cannabinoids: The Current State of Evidence and Recommendations for Research. Washington (DC): National Academies Press US; 2017.

3 Jugl S, Okpeku A, Costales B, Morris EJ, Alipour-Haris G, Hincapie-Castillo JM, et al. A Mapping Literature Review of Medical Cannabis Clinical Outcomes and Quality of Evi- dence in Approved Conditions in the USA from 2016 to 2019. Med Cannabis Cannabinoids. 2021;4(1):21-42.

4 Consortium for Medical Marijuana Clinical Outcomes Research. Annual Report 20192020. 2020 [cited April 19, 2021]. Available from: https://mmjoutcomes.org/our-consortium/annualreport/.

5 Consortium for Medical Marijuana Clinical Outcomes Research. Annual Report 20202021. 2021 [cited April 19, 2021]. Available from: https://mmjoutcomes.org/our-consortium/annualreport/.

6 Consortium for Medical Marijuana Clinical Outcomes Research. Program and Abstract Book: Consortium for Medical Marijuana Clinical Outcomes Research 2021 [cited May 22, 2021]. Available from: https://secureservercdn.net/166.62.112.107/upb.57c.myft- pupload.com/wp-content/uploads/2021/04/ CCORC-Program-Abstract-Book-1.pdf.

7 Abrams DI, Jay CA, Shade SB, Vizoso H, Reda $\mathrm{H}$, Press S, et al. Cannabis in painful HIV-associated sensory neuropathy: a randomized placebo-controlled trial. Neurology. 2007 Feb;68(7):515-21.

8 Abrams DI, Vizoso HP, Shade SB, Jay C, Kelly ME, Benowitz NL. Vaporization as a smokeless cannabis delivery system: a pilot study. Clin Pharmacol Ther. 2007 Nov;82(5):572-8.

9 Kosel BW, Aweeka FT, Benowitz NL, Shade SB, Hilton JF, Lizak PS, et al. The effects of cannabinoids on the pharmacokinetics of indinavir and nelfinavir. AIDS. 2002 Mar;16(4):543-50.

10 Abrams DI, Couey P, Shade SB, Kelly ME, Benowitz NL. Cannabinoid-opioid interaction in chronic pain. Clin Pharmacol Ther. 2011 Dec;90(6):844-51. 